

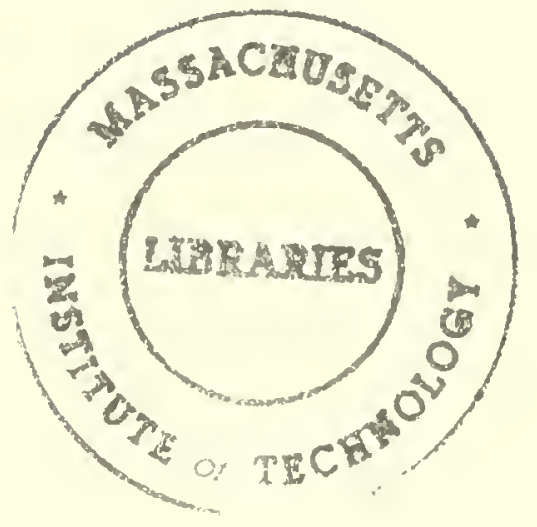




$\mathrm{HD} 28$

. M414

110.3395

$-92$

\section{WORKING PAPER \\ ALFRED P. SLOAN SGHOOL OF MANAGEMENT}

ON THE PERSISTENCE OF RESEARCHERS IN

TECHNOLOGICAL DEVELOPMENT

Raghu Garud

New York University

December 1991
Michael A. Rappa

Massachusetts Institute of

Technology

Sloan WP \# 3395-92

\section{MASSACHUSETTS}

INSTITUTE OF TECHNOLOGY

50 MEMORIAL DRIVE

CAMBRIDGE, MASSACHUSETTS 02139 


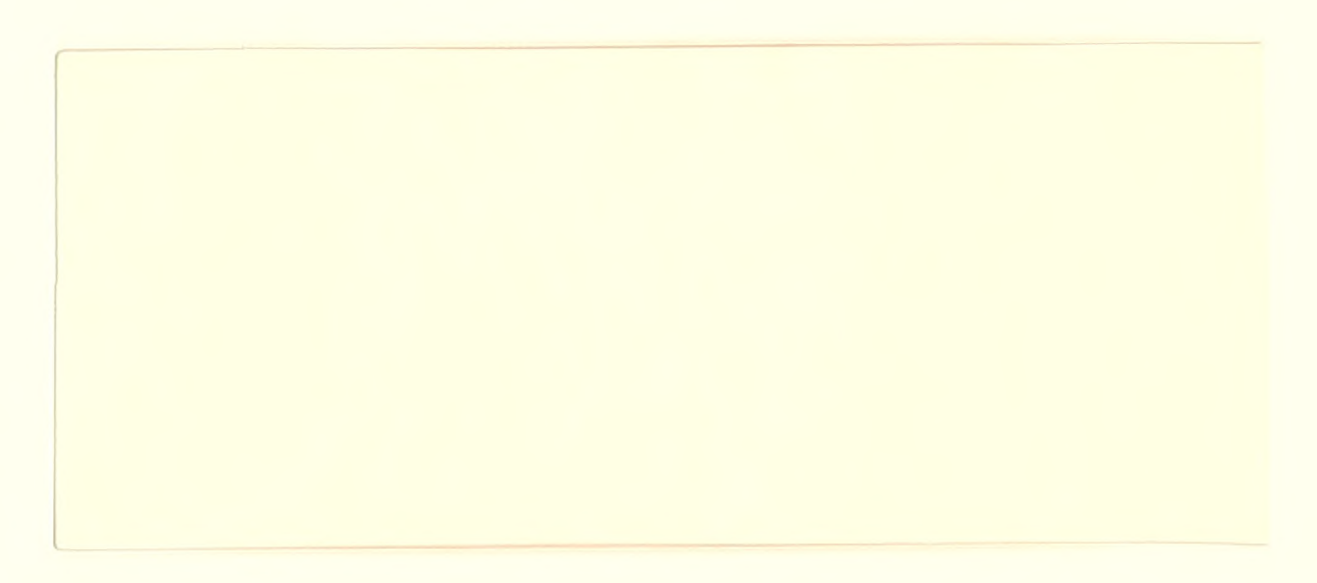




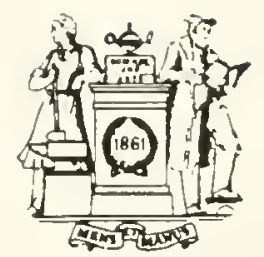

Massachusetts Institute of Technology

\section{ON THE PERSISTENCE OF RESEARCHERS IN TECHNOLOGICAL DEVELOPMENT}

$$
\begin{gathered}
\text { Raghu Garud } \\
\text { New York University }
\end{gathered}
$$

\author{
Michael A. Rappa \\ Massachusetts Institute of \\ Technology
}

December 1991

Sloan WT \# 3395-92

C I99I MASSACHUSETTS INSTITUTE OF TECHNOLOGY

Alfred P. Sloan School of Management

Massachusetts Institute of Technology

50 Memorial Drive, E52-538

Cambridge, MA 02139-4307 
- 1. LBRARIES

O 91992

CLStat \& L 


\title{
ON THE PERSISTENCE OF RESEARCHERS IN TECHNOLOGICAL DEVELOPMENT
}

\author{
Raghu GARUD \\ New York University
}

\author{
Michael A. RAPPA ${ }^{\dagger}$ \\ Massachusetts Institute of \\ Technology
}

December 1991

\section{ABSTRACT}

\begin{abstract}
Researchers often persist in their efforts to create knowledge that shapes the development of a technology. By persisting, researchers can master a stock of knowledge and then contribute to its development. However, undue persistence can be detrimental to researcher's careers and the well-being of the organizations they work for. This is because undue persistence can lead to obsolescence of existing stocks of technological knowledge. Specific hypotheses on persistence are developed and tested using the scientific and technical literature to determine the length of association of individual researchers.
\end{abstract}

\section{INTRODUCTION}

New fields of science and technology emerge through the efforts of researchers who engage in problem solving activities. These efforts lead to the creation of ideas and techniques that represent technological knowledge (Allen, 1966; Layton, 1977:198; Rosenberg, 1982:143; Laudan, 1984). Accordingly, the study of technological change becomes one of understanding the creation and diffusion of knowledge among practitioners.

A widely accepted model of the growth of knowledge is one that views it as a cumulative progression of ideas and techniques (Crane, 1972:26). Antecedent ideas and techniques influence the choice of future problems (Dosi, 1982). Success in solving these problems depends upon the acquisition of relevant experiences over time. These experiences translate into "rules of thumb" (Sahal, 1981:111) or "search heuristics" (Nelson and Winter, 1982) that researchers employ to address their technological problems. In this

† This work is fully collaborative; the listing of authors is arbitrary. Raghu Garud is assistant professor of management, New York University, Stern School of Business (40, West 4th Street, Room 623, New York, NY 10003; tel. 212-998-4123). Michael Rappa is assistant professor of management, Massachusetts Institute of Technology, Sloan School of Management (50 Memorial Drive, Cambridge, MA 02139; tel. 617-2533627). The authors are indebted to Susan Bjorner and Gary Quick for their assistance in creating the database and Joel Baum, Hayagreeva Rao and Robert Yaffee for their comments and guidance. 
way, technological progress is a cumulative problem-solving process with only infrequent major disruptions (Rosenberg, 1982: 63).

The cumulative growth of technological knowledge has important implications for the behavior of researchers who produce it. In particular, researchers may first need to master a core stock of knowledge before they can contribute to its growth. Herber Simon estimates that it may take anywhere up to ten years to become an expert in an area of work. That is, researchers have to persist in their efforts to develop a new technology in order to contribute to its development.

Recognizing the benefits of persistence, Ziman (1987) nevertheless cautions against the decreasing marginal returns from undue persistence. According to Chubin and Connolly (1982), researchers persisting unduly with an area of work in order to leave a research trail. Over time, this type of behavior leads to incremental yields from a stock of knowledge.

The danger of undue persistence is that existing researchers' stock of knowledge may become obsolete, thereby undermining the well being of the organizations they work for. Indeed, many scholars have witnessed the creation of new technological knowledge by researchers from outside the system. These "outside" researchers offer ideas that may run counter to existing mainstream technological knowledge. If successful, the new knowledge displaces existing knowledge.

What determines researchers' persistence with a technology? While an important question that has clear implications for the management of $R \& D$ organizations, this question has so far not been examined empirically. In this paper, we use the literature as a source of data on the length of researchers' association with a technology to examine persistence behavior. Persistence, we suggest, depends upon individual, relational and collective aspects of the knowledge crearion process that technological change entails. Persistence is also influenced by the occurrence of important events in the development of a technology that legitimize it. Before proceeding to develop and test hypothesis on persistence, we first provide an overview of the knowledge creation process within a community of researchers.

\section{RESEARCH COMMUNITIES AND THE CREATION \\ OF TECHNOLOGICAL KNOWLEDGE}

In introducing the trade-offs between persistence and undue persistence, researchers were deliberately portrayed as individuals working independently on technological 
problems. However, it is more realistic to visualize researchers as working in collaborative relationships with one another. Collaboration between researchers possessing different competencies is vital to address complex indivisible technological problems (Metcalfe and Soete, 1983) that researchers individually may not able to address.

The creation of knowledge by researchers engaged in collaborative relationships with others results in a steady accumulation of knowledge that other researchers can build upon. From this perspective, the creation of a new technology is a collective endeavor. Braun and MacDonald's (1978) illustrate the collective nature of technological change and the knowledge creation it entails. They point out that it is unrealistic to see the transistor as the product of three men, or of one laboratory, or of physics, or even of the forties. Rather, the development of the transistor required contributions from hundreds of researchers, working in many different places, in many different fields, over many years.

Technological knowledge as a collective endeavor also becomes manifest in the acceptance of practices that become institurionalized within a community of researchers (Jagtenberg, 1983). These practices consist of testing standards (Constant, 1987), inscription devices (Latour and Woolgar, 1979), and other taken for granted facts and artifacts. These institutionalized practices legitimize a technology, thereby creating the necessary technological momentum (Hughes, 1987) that attracts other researchers. As researchers join a technological field, there is an increase in the rapidity with which technological knowledge is created.

Technological knowledge has another collective property that has important implications for its creation and diffusion. In particular, the knowledge creation process is fraught with externalities; that is, even those who have not contributed to its creation may appropriate its benefits. The presence of externalities leads to the rapid diffusion of technological knowledge. However, the presence of externalities also reduces the incentives for the private production of knowledge. Despite mechanisms such as intellectual property rights, knowledge does leak out to others. As a consequence, Nelson (1959) and Arrow (1962) have argued that the private production of knowledge may be sub-optimal from a community perspective. Under these circumstances, researchers in the public sector perform important roles in the creation and dissemination of knowledge (Rosenbloom, 1966; Mueller, 1962; Utterback, 1975; Stobaugh, 1985). Besides engaging in research activities, researchers in public institutions identify and fund private institutions for the creation of knowledge. 
Rappa and Debackere (1991) introduce the notion of researcher community to integrate these various facets of the knowledge creation and diffusion process. Building upon Constant's (1980) work, Rappa and Debackere define the researcher community as a group of scientists and engineers who are committed to solve a set of inter-related scientific and technological problems. These researchers may be organizationally dispersed in public and private sector organizations but communicate in some way with each other. Within the community, knowledge creation is a collective endeavor driven by individuals engaged in collaborative relationships with others. Consequently, persistence is in some way determined by individual, relational, and collective aspects of the knowledge creation and diffusion process within this community. We explore these aspects in greater detail in the next section.

\section{DETERMINANTS OF PERSISTENCE}

Analogous to Kuhn's (1970) notion of anomalies in science, Constant (1987) introduces the notion of presumptive anomalies that occur in the development of technologies. Presumptive anomalies occur when assumptions derived from science indicate that a conventional technology will fail, or that a radically different technology will be more effective (Constant, 1980:15). The identification of presumptive anomalies may result in the displacement of established technologies and the knowledge systems they entail. Existing researchers resist these discontinuous changes because of career commitments to their own technologies. Besides this instrumental reason for resisting the introduction of a new technology, researchers also resist changes for cognitive reasons. The new stock of knowledge represents a new technological paradigm (Dosi, 1982), or regime (Nelson and Winter, 1977), with its associated traditions of testability (Constant, 1987). Dosi (1982:153) points out that these paradigms have a powerful "exclusionary effect" rendering researchers blind to alternative technological possibilities.

Confronting resistance from researchers embedded in an existing technological paradigm, the new technology can only grow with the efforts of a few dedicated researchers to pursue the development of the new technology. These pioneering researchers draw upon the skills and knowledge of researchers from other disciplines who may be peripherally connected with the development of the new technology. These peripherally connected researchers may make transient contributions to the emerging technology without committing themselves to its long term development. 
Transient contribution behavior from these peripherally connected researchers may have its own value during early periods of technology development. However, sustained contributions from a growing number of researchers are necessary for the success of the new technology. As long as the new technology lacks legitimacy, researchers will be unwilling to commit themselves to developing it. Events that legitimize the new technological field are therefore critical to induce researchers' commitment.

Constant (1987) offers the notion of traditions of testability as one approach by which legitimacy can be established for the the new technology. Traditions of testability consist of a set of testing techniques and normative values that sustains and defines the specific technological practice. Akin to the formation of a new vocabulary and a grammar, these traditions of testability help researchers communicate with one another and to legitimize the new technology.

Technologies also can gain legitimacy from the actions and statements of powerful institutional organizations. Examples of events that serve to legitimize technologies include: seed capital from federal funding agencies, endorsements from regulatory bodies, and the formation of professional organizations. In combination with the formation of traditions of testability, these events that lend legitimacy to the new technology result in increasing the commitment of researchers to the development of the technology.

$\mathrm{H} 1$ : Researchers are more likely to persist in their efforts to develop a technology in a legitimized field.

Besides these events that legitimize the new technological field, the presence of a critical mass of researchers may be required to establish technological momentum. Size confers power and prestige to the emerging community. Power and prestige result in the community's ability to generate resources from the environment that sustains individual researchers in their problem solving efforts. Thus, researchers are more likely to persist once the community size increases beyond a threshold limit as a bandwagon effect occurs (Rappa and Debackere, 1989).

H2: Researchers are more likely to persist in their efforts to develop a technology after the development of a critical mass of researchers.

Over time, practices followed by these researchers become institutionalized within this community and begin dictating the direction of future research. Representing collective specialized stocks of knowledge, these practices become accessible only to those who undergo professionalized education and training. As investments required to enter the 
community increases, it becomes more difficult for researchers to exhibit transient contribution behavior. As a result, researchers who join a professionalized research community will attempt to leverage their entry investments with ongoing contributions.

H3: Researchers' persistence is likely to increase with the accumulation of knowledge within a technological field.

Individual researchers may pursue different technological trajectories within these emerging paradigms (Dosi, 1982). Trajectories represent specific directions of technological change based on researchers' theoretical assumptions and the physical artifacts they employ. Early during the development of a technology, researchers hold different beliefs about "what is feasible or at least worth attempting" (Nelson and Winter, 1982:258-259). Because of the uncertainty and ambiguity associated with technological choices, researchers "place their bets" on different trajectories.

Over time, researchers develop technology specific competencies. These competencies build up in a path dependent manner (Cohen and Levinthal, 1990; Arthur, 1988; David, 1987) as earlier technological choices direct future options and solutions. As comperencies become specialized, researchers find it increasingly difficult to re-deploy them to pursue other trajectories, or to pursue other technological paradigms. As a consequence, there are powerful incentives for researchers to persist with a trajectory.

Thus, an important determinant of persistence is the longevity of association with the technology itself. Gieryn's (1978) work supports this hypothesis. Studying the published work of American astronomers over the period 1950-1975. Gieryn found that researchers who had published a paper on a particular specialized subject were likely to continue publishing in the same area for many years. Similarly, Mullins (1972) found that the mean length of membership of a Phage group of researchers was about three years, but doubled to six years if those who published only one paper on the subject were excluded.

H4: The likelihood of persistence in the development of a technology increases with duration of researcher's association with a technology.

So far, we have examined individual and collective dimensions that influence persistence of researchers. Besides these dimensions, persistence is also determined by relational aspects that capture the extent to which researchers associated with the development of a technology collaborate with one another. Collaboration represents the joint creation of ideas by individuals. In a recent study of a bio-medical research community, Small and Greenlee (1986) found that collaboration between researchers 
increased steadily over the ten year period that they studied. Beaver and Rosen (1979) found a similar pattern of increased collaboration from their study of scientists. They concluded that the growth of collaboration to be a natural consequence of professionalization.

Professionalization implies the division of labor and specialization among researchers. The specialized division labor of requires collaborative efforts where different skills can be brought to bear to address complex technological problems (Ziman, 1987; Jagtenberg, 1983). Collaboration thus increases the reach of individual researchers, thereby allowing them to persist with their contributions.

H5: Researchers are more likely to persist in their effort to develop a technology if they collaborate with others.

\section{RESEARCH SITE}

We chose the field of cochlear implants as an illustrative case for the present analysis. Although studies of the electrical stimulation of the ear have a long history, it was not until the 1950s that researchers began the systematic investigation of how electrical stimulation might provide a means for enabling people with sensorineural deafness to gain some sense of sound. One result of this research was the advent of the cochlear implant, a device that uses electrical stimulation of the cochlea to provide a sense of sound to profoundly deaf people.

One of the first trials of a rudimentary cochlear implant devices was performed in 1961 by William House, a clinical physician, who later founded the House Ear Institute, a major center for cochlear implant research. At first, few researchers took an interest in cochlear implants, largely due to the intense controversy the field encountered. Many considered the device to lack a scientific basis and believed it was too premature for human experimentation. It was not until the early 1970s that the controversy subsided and cochlear implants emerged as a viable research field. Several meetings were held in 1973 that galvanized the burgeoning field. These meeting included a workshop held as part of the American Otological Society meeting (a group that was adamantly opposed to the topic in previous years) and the first international conference on the subject.

One study of importance is Bilger's work initiated in 1975 on the comparative performance of cochlear implants. Funded by the U.S. National Institutes of Health and 
released in 1977, the "Bilger report" (1977) showed that although the early claims regarding performance were exaggerated, cochlear implants did have merit. In its conclusion, the report lent some sorely needed legitimacy to the field and thereby opened the door for a greater number of researchers to participate. By 1991, there were about four hundred individuals active in the field employed in nearly one hundred different organization world wide. About forty percent of the cochlear implant community is located in the U. S. Although tremendous progress has been made over the years, and about three thousand patients have received the cochlear devices, the cochlear implant remains largely an experimental procedure with many challenging problems yet to be overcome.

\section{DATA COLLECTION AND METHODS}

Gathering longitudinal data on researcher persistence in a field is not a simple task. First, it requires some degree of historical investigation. If we simply ask everyone who presently works in a particular field how long they have participated, we would overlook the experience of many individuals who have already come and gone over the years. Second, the number of researchers who have participated in a field can be quite large and can be widely dispersed geographically thereby making it very hard to ascertain the extent of their participation. Confronted with these constraints, it become appealing to look to the literature as a source of data about who participates in a field and for how long.

Journal articles, conference papers and patents in a given field represent a detailed, self reported archival record of the effort generated by researchers to solve the scientific and technological problems confronting them. Furthermore, the literature is an appealing source of data in several respects: the publication conventions ensure a level of quality and authenticity; the data can be collected unobtrusively; the findings can be replicated and tested for reliability; and the data are publicly available and not very expensive to collect. When taken together, the literature can be viewed as a unique chronology of the efforts of researchers to establish a new field, and can provide information about the researchers involved, how long they were involved, where they were employed, who they collaborated with, what problems they pursued, and when they were active in the field. Clearly, it would be difficult to match the comprehensive scope and longitudinal nature of the literature using other data collection techniques.

Data collection. Five commercial electronic databases (covering the medical sciences and engineering literature) were used to identify publications related to the field of 
cochlear implants. The databases were searched using a set of key terms that are known to be commonly used in the lexicon of cochlear implant researchers. These key terms might be either in the title, abstract or classification terms of a document. The search strategy was derived from an earlier one used by the National Library of Medicine to creare a research bibliography on cochlear implants.

The data collection procedure resulted in the identification of 1329 unique documents relating to cochlear implants published between 1973 and 1989. The data base was then used to identify each researcher who contributed to the field over the seventeen year period. This procedure yielded a total of 1,257 researchers. A statistical database was created containing several individual-, relational-, and population-level variables for each researcher that was derived from information obtained from published documents.

Dependent variable. The number of years spanning a researcher's first and last known publications in a field-that is the "contribution span" - serves as a unique and useful measure of researchers persistence in a field. Although calculating the contribution span is relatively straightforward, there are some methodological issues that arise that require further explanation. The primary issue of concern is that for those researchers who presently are active in cochlear implants, the overall length of contribution is indeterminate: that is, since the individual have not yet left the field, it is only known that the length of their contribution is some minimum value (that is the entry year to the present year). To account for this, survival analysis statistics were used to analyze the data. Such techniques take into consideration precisely this kind of problem in the calculations with a procedure that adjusts for the biases that right censored data create.

Determining if a researcher is still active can be difficult in certain conditions. The reason for this is that researchers may not publish every year. Therefore, a researchers' contribution span in the field can be characterized by gaps of several years in duration in which there are no publications to their credit. The existence of discontinuities in publication records raise the issue of how frequently a researcher must publish in order to be considered an active contributor to the field. Thus, understanding the nature and the prevalence of gaps in a researchers' contribution span is important in determining the proper censoring scheme to use in the analysis. The question arises: How long after someone ceases to publish is it reasonable to assume they are no longer in the field? The answer to this question is necessary in order to determine who has exited the field and who persists. 
The cochlear implant data shows that $242(19 \%)$ researchers have a gap in their contribution spans. Among those who have a gap in their contribution spans, four out of five researchers have a gap of three years or less in duration. Based on this evidence, we decided that researchers who had published within the past three years of the last year of the data set (1989) would be censored.

Only a small number $(3.7 \%)$ of all the researchers have a gap between publications of longer than three years in duration. These sparse contribution spans may be indicative of individuals who do not contribute continuously to the field. We treated these researchers as having left the field if they did had contributed during a three year period, and as having begin a new cycle when they again started contributing.

Explanatory variables. Several variables were created that might account for heterogeneity among researchers. These include the kind of organization in which each researcher was employed. These researchers were coded according to whether they reside in an academic, industrial, government or independent research laboratories.

Besides these variables, other explanatory variables were created to test the four hypotheses developed on contribution spans. To test for the hypothesis on legitimacy, a variable was created to distinguish between a pre-legitimacy period (considered to be prior to the publication of the Bilger report in 1978) and a post-legitimacy period after 1978.

To test for the hypothesis on critical mass, a variable that measured the population size was created. Population size is measured in terms of the number of researchers who published in the field in a given year. A second order population variable was also created to capture any quadratic associations between population size and contribution spans. Besides these two variables, a third variable at the population level was created to control for possible influence of dispersion of researchers among different organizations on persistence. This dispersion variable measured the extent to which the community is concentrated in a few organization or spread across many. For this purpose, a Hirfindahl statistic, which is determined by calculating the sum of the squared share of researchers affiliated with each organization is used.

A variable was created that represented the accumulated knowledge in the field as determined by the cumulative number of publications to test for the hypothesis on growth of knowledge in the field. To test the hypothesis at the individual level, a variable that was 
the time of researchers' association with the technology was created. Chubin and Connolly (1982) suggest a potential alternative explanation for individual persistence. They point out that persistence can be a result of positive feedback relationship between successful researchers and their ability to gather additional resources from the environment. To control for this alternative explanation, we developed a measure of the cumulative productivity of individual researchers.

Collaboration was measured by the number of unique individuals that a researcher had associated with as a co-author on publications. To control for orher potential group level explanations, two group level variables were created to reflect the size and productivity of a researchers' institutional affiliation. The size of a researcher's group is measured in terms of the number of individuals affiliated with that organization who also publish in the field. Cumulative group productivity is measured as the cumulative number of cochlear implant publications by individuals affiliated with a researchers' group.

\section{MODELING STRATEGY AND RESULTS}

Model: Event history methods were used to study persistence behavior of researchers. Persistence implies a lower probability of exiting a field conditional upon earlier association. The conditional probability of exiting the field is the exit rate. The instantaneous exit rate, also known as the hazard rate, is:

$$
r_{i}(t)=\lim _{t \rightarrow 0} \frac{\operatorname{Pr}(t, t+\Delta t / t)}{\Delta t}
$$

The exit rate at time $t$ was modeled by estimating the following specification:

$$
r_{i}(t)=\exp \left[a_{i} X(t)\right]
$$

Where $X(t)$ is a vector of the values of the covariates at time $t$, and ai is a vector of parameters. In this model, hazard rates are postulated to be log-linear functions of the variables $\mathrm{X}$. In order to incorporate time variations in the explanatory variables, a multiple-spells formulation of this model was used. In the multiple spells formulation, each period is broken down into one-year observations in which the researcher is at risk of exiting. Each of these annual spells is treated as being right censored unless the researcher 
exits. RATE (Tuma, 1980) was used to estimate the vector of parameter estimates by the method of maximum likelihood.

Results. The model was estimated in a sequence of steps by adding sets of explanatory variables into the equation (see Table 1). First, variables pertaining to researcher type were included to control for variations among researchers' persistence because of organizational affiliation. The second model included the length of researchers' association along with the variable on cumulative productivity. This model was estimated to identify whether persistence may be an age dependent phenomenon after controlling for possible heterogeneity of the sample, and controlling for researcher success and reputation as measured by the cumulative productivity variable. Models 3 to 6 added variables that tested hypotheses 1 to 4 . As explained in the methods section, appropriate control variables were also introduced at each step.

The results indicate that the fit of the models improved as covariates were included: The $\chi^{2}$ rises from 18 in Model 1 to 614 in Model 6. Model 6 displays the effects of all covariates on the exit rate. For this paper we focus our attention on the results displayed in Model 6 even though results of other models are provided for a comparison.

The results indicate that the hypothesis relating to collaboration was the only one among the five that did not receive support. One reason for this is that collaboration as measured by the number of cumulative co-authors does not adequately capture the entire spectrum along which researchers collaborate. Nevertheless, the lack of significance suggests that relational aspects are less of a predictor of persistence. This conclusion is bolstered by the lack of significance of other group level variables, including group size and group productivity.

The results do support other hypotheses. For instance, the positive sign of the legitimacy variable suggests that the likelihood of persistence increased after 1978 with the publication of the Bilger Report that served to legitimize the cochlear implant field. Similarly, there is support for the critical mass hypothesis. The positive coefficient of the population variable combined with the negative coefficient of the second order term implies an inverted U-shaped relationship between population size and the hazard rate. Critical mass appears to have been accomplisheed with a population size of around 213 researches (which occurred in 1983) at which point the hazard rate decreases. 
In support for the hypothesis relating to knowledge accumulation and persistence, the variable that reflects the cumulative publications in the field was found to be significant with a negative sign. That is, the risk of leaving the field decreases as the accumulated knowledge increases.

The significant negative sign of the length of association variable indicates that researchers may have a tendency to persist with time despite controlling for the cumulative productivity of researchers. To further explore individual determinants of persistence over time, we conducted a non-parametric analysis of the hazard function based on the duration of researchers' association. For this purpose, we used the lifetable approach in SAS (v5.18) procedure LIFETEST (see Figure 1).

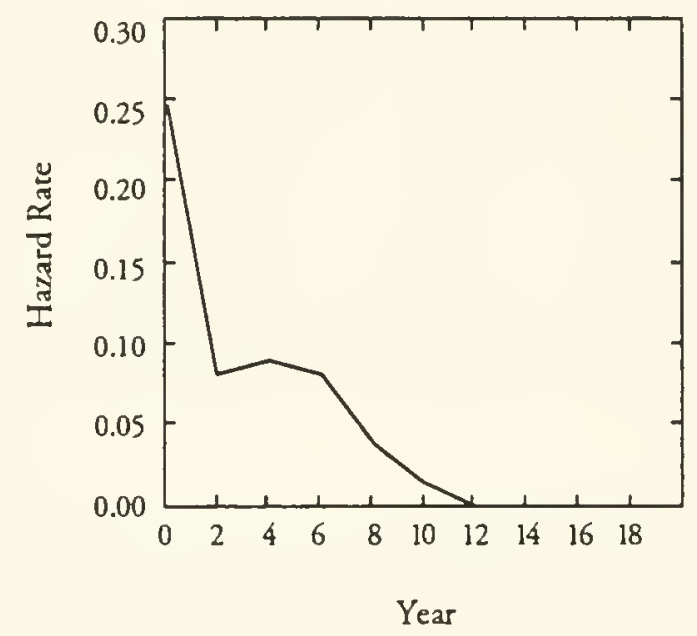

FIGURE 1: Hazard function for cochlear implant researchers

The hazard rate decreases very rapidly for researchers who have contribution spans of at least two years, that is, the probability of a researcher ceasing to contribute after having contributed for two years is only about 0.08 compared to about 0.25 for a researcher in the field only one year. The hazard rate stabilizes for researchers whose contribution spans are between two and six years, and then diminishes rapidly between six and twelve years. The basic implications of the hazard function is that the longer a researcher contributes to the freld, the less likely he or she is to leave it, with the first and sixth years being particularly critical points. Indeed, the risk of leaving the field is the highest within the first year. 


\section{CONCLUSION}

The objective of this paper was to empirically explore persistence behavior of researchers associated with the development of a technology. Non-parametric estimates of the analysis of persistence through a hazard analysis shows that the risk of exiting the field is greatest in the first year of their contribution. About 40-percent of the researchers associated with cochlear implants demonstrate transient persistence for only a one year duration. The hazard rate declines sharply after the first year and remains fairly constant until the sixth year after which it continues to decline rapidly.

This result might have an explanation in a behavioral characteristic of the research process. For example, a researcher might be drawn to a field by the prospect of making an imporant contribution and by the possibility of attracting the resources to underwrite the cost of his or her work. Barring success at either, the researcher might exit the field shorly thereafter for more fertile territory. But if the researcher can initially "survive" in the field, a research program might be established; once in place it would require several years of data collection and analysis. By the end of the sixth year, a critical point is reached, at which time the success of the program leads the researcher to remain in the field with little probability of ever leaving. It is among these latter category of researcher that we would look for undue persistence.

Modeling the instantaneous exit rate with parametric statistics provided other insights about persistence. Early during the development of a technology, persistence is strongly associated with the legitimacy of the technology and the size of the research community. During this stage, the creation of technological momentum has very much to do with whether or not individuals are ready to commit themselves to the emerging technology to sustain its growth. Over time, a reversal occurs wherein accumulated knowledge results in creating strong incentives for researchers to persist.

What is perhaps most interesting is that relational aspects including direct collaboration and other forms of collaboration including group membership and group productivity do not appear to be key determinants of persistence. Persistence thus appears to be determined by individual efforts to contribute in an emerging professionalized field with its concomitant norms for the creation and diffusion of technological knowledge as opposed to intermediary relational aspects of the knowledge creation process.

This is a preliminary analysis that sets the base for the exploration of more finegrained processes connected with researcher persistence. For instance, data from the 
cochlear implant literature have been gathered with respect to the nature of the work being conducted by each researcher (such as basic research, applied research, development, or clinical research), and the particular technological trajectory each researcher has pursued (such as single-channel versus multi-channel devices). Other kinds of data such as annual funding levels and the extent of the market commercialization have been collected for conducting a subsequent analysis. 


\section{REFERENCES}

Allen, T.J. 1966. "Studies of the problem-solving process in engineering design," IEEE Transactions on Engineering Management, EM-18: 72-83.

Arrow, K.J. 1962. "Economic welfare and the allocation of resources for innovative activity, ${ }^{n}$ in R.R Nelson (ed.) The Rate and Direction of Inventive Activity. Princeton: Princeton University Press.

Arthur, B. 1988. "Self-reinforcing mechanisms in economics," in P Anderson et al., The Economy as an Evolving Complex System. Reading, Mass.: Addison-Wesley.

Beaver D. and Rosen R. 1978. "Studies in scientific collaboration: Parts 1, $2 \& 3^{n}$ Scientometrics, 1: 65-245.

Bilger, RC., et al. 1977. "Evaluation of subjects presently fitted with implanted auditory prosthesis," Annals of Otology, Rhynology, and Laryngology, 86, 3, Part 2, Suppl. 38.

Braun, E. and MacDonald, S. 1978. Revolution in Miniature: The History and Impact of Semiconductor Electronics. Cambridge: Cambridge University Press.

Chubin, D.E. and Connolly, T. 1982. "Research trails and science policies: Local and extra-local negotiations of scientific work" in Elias, N., et al. (eds.) Scientific Establishments and Hierarchies. Dordrecht: Reidel.

Cohen, W. M. and Levinthal, D. A. 1990. "Absorptive capacity: A new perspective on learning and innovation," Administrative Sciences Quarterly, 35, 1:128-52.

Constant, E.W. 1980. The Origins of the Turbojet. Baltimore: John Hopkins University Press.

Constant. E.W. 1987. "The social locus of technological practice: Community, system, or organization?," in W.E. Bijker, et al. (eds.) The Social Construction of Technological Systems. Cambridge, Mass.: MIT Press.

Crane, D. 1972. Invisible Colleges: Diffusion of Knowledge in Scientific Communities. Chicago: University of Chicago Press.

David, P. 1985. "Clio and the economics of QWERTY" Economic History, 75: 227-332.

Dosi, G. 1982. "Technological paradigms and technological trajectories," Research Policy 11: 147-162.

Gieryn, T.F. 1978. "Problem retention and problem change in science," Sociological Inquiry, 48: 96-115.

Hull, D.L. 1988. Science as a Process: An Evolutionary Account of the Social and Conceprual Development of Science. Chicago: University of Chicago Press. 
Hughes, T.P. 1987. "The evolution of large technological systems," in W.E. Bijker, et al. (eds.) The Social Construction of Technological Systems. Cambridge, Mass.: MIT Press.

Jagtenberg, T. (1983), The Social Construction of Science: A Comparative Study of Goal Direction, Research Evolution and Legitimation. Boston: Reidel Publishing.Co.

Kuhn, T.S. 1970. The Structure of Scientific Revolutions. Chicago: University of Chicago Press (2d ed.).

Latour, B. and S. Woolgar. 1979. Laboratory Life: The Social Construction of Scientific Facts. Beverley Hills: Sage Publications.

Laudan, R. 1984. The Nature of Technological Knowledge. Dordrecht: Reidel.

Layton, E. 1977. "Technology as knowledge", Technology and Culture, 15: 31-41

Mansfield, E. 1985 "How rapidly does a technology leak out?" Journal of Industrial Economics, 34, 2: 217-223.

Metcalfe, J. S. and Soete, L. 1983. "Notes on the evolution of technology and international competition," a paper presented at the workshop on Science and Technology Policy, University of Manchester.

Mullins, N.C. 1972. "The development of a scientific speciality: The phage group and the origins of molecular biology," Minerva, 10: 51-82.

Mueller, W.F. 1962. "The origins of the basic inventions underlying Du Pont's major product and process innovations, 1920-1950," in R. Nelson (ed.) The Rate and Direction of Inventive Activity. Princeton: Princeton University Press.

Nelson, R 1959. "The simple economics of basic scientific research", Journal of Political Economy, 6: 297-306.

Nelson, R and S.G. Winter. 1977. "In search of a useful theory of innovation," Research Policy. 6: 36-76.

Nelson, R. and S.G. Winter. 1982. An Evolutionary Theory of Economic Change. Cambridge, Mass.: Harvard University Press.

Rappa, M.A. 1989. "The dynamics of R\&D communities: Implications for technology strategy," working paper, MIT Sloan School of Management.

Rappa, M.A. and Debackere, K. 1991. "R\&D communities and technological development," working paper, MIT Sloan School of Management.

Rosenberg, N. 1982. Inside the Black Box: Technology and Economics. Cambridge: Cambridge University Press.

Rosenbloom, R.S. 1966. "Product innovation in a scientific age," in New Ideas for Successful Marketing. Chicago: Proceedings of the 1966 World Congress, American Marketing Association, Chapter, 23. 
Sahal, D. 1981 Patterns of Technological Innovation. Reading, Mass.: Addison-Wesley Publishing Company.

Small, H. and Greenlee, E. 1986. "Collagen research in the 1970s," Scientometrics, 10 (12): $95-117$.

Stobaugh, R. 1985. "Creating a monopoly: Product innovation in petrochemicals," in R. Rosenbloom (ed), Research on Technological Innovation, Management and Policy, Vol. 2. New York: JAI Press (81-112).

Tuma, N.B. 1980. Invoking RATE, (2nd ed.). Menlo Park, Calif.: SRI International.

Tuma N.B. and Hannan, M.T. 1984. Social Dynamics: Models and Methods. Orlando: Academic Press.

Utterback, J.M. 1974. "Innovation in industry and the diffusion of technology," Science, 183: 620-26.

Ziman, J. 1987. Knowing Everything About Nothing: Specialization and Change in Scientific Careers. Cambridge: Cambridge University Press. 


\section{IABLE I}

ML Estimation of Contribution Spans

\begin{tabular}{|c|c|c|c|c|c|c|}
\hline & Modell & Medel2 & Model3 & Medels & Medel5 & Medel6 \\
\hline Intercept & $\begin{array}{c}-1.5^{* * *} \\
(0.06)\end{array}$ & $\begin{array}{l}-.7^{-\cdots} \\
(0.08)\end{array}$ & $\begin{array}{c}-.7^{2 \cdots .8} \\
(0.08)\end{array}$ & $\begin{array}{c}-2.5^{\cdots .} \\
(0.45)\end{array}$ & $\begin{array}{c}-1.77^{\prime \cdots} \\
(0.47)\end{array}$ & $\begin{array}{c}-1.8 \% \\
(0.47)\end{array}$ \\
\hline \multicolumn{7}{|l|}{ Iype of Orgarization } \\
\hline Industrial & $\begin{array}{l}.001 \\
(0.26)\end{array}$ & $\begin{array}{c}.06 \\
(0.26)\end{array}$ & $\begin{array}{c}.1 \\
(0.26)\end{array}$ & $\begin{array}{c}.1 \\
(0.26)\end{array}$ & $\begin{array}{c}.07 \\
(0.26)\end{array}$ & $\begin{array}{c}.04 \\
(0.26)\end{array}$ \\
\hline Research & $\begin{array}{c}.13 \\
(0.1)\end{array}$ & $\begin{array}{l}.012 \\
(0.1)\end{array}$ & $\begin{array}{c}.03 \\
(0.1)\end{array}$ & $\begin{array}{r}-.01 \\
(0.1)\end{array}$ & $\begin{array}{r}-.01 \\
(0.1)\end{array}$ & $\begin{array}{l}.007 \\
(0.1)\end{array}$ \\
\hline Government & $\begin{array}{l}1.5^{\circ} \\
(0.58)\end{array}$ & $\begin{array}{l}1.11 \\
(0.58)\end{array}$ & $\begin{array}{l}1.16^{\circ} \\
(0.58)\end{array}$ & $\begin{array}{c}.71 \\
(0.58)\end{array}$ & $\begin{array}{l}.58 \\
(0.58)\end{array}$ & $\begin{array}{l}.47 \\
(0.58)\end{array}$ \\
\hline \multicolumn{7}{|l|}{ Geographic bection } \\
\hline USA & $\begin{array}{c}-.03^{\ldots *} \\
(0.09)\end{array}$ & $\begin{array}{c}-.22^{\circ} \\
(0.085)\end{array}$ & $\begin{array}{l}-.22^{* *} \\
(0.08)\end{array}$ & $\begin{array}{l}-.02^{*} \\
(0.09)\end{array}$ & $\begin{array}{l}-.16 \\
(0.09)\end{array}$ & $\begin{array}{c}-.15 \\
(0.086)\end{array}$ \\
\hline Length of association & & $\begin{array}{l}-.28^{m . .} \\
(0.046)\end{array}$ & $\begin{array}{l}-.28^{\mathrm{*t*}} \\
(0.046)\end{array}$ & $\begin{array}{c}-.29^{* . *} \\
(0.05)\end{array}$ & $\begin{array}{c}-.27^{* *} \\
(0.0 .4)\end{array}$ & $\begin{array}{c}-.27^{* \cdots} \\
(0.05)\end{array}$ \\
\hline Cumulative researcher productivity & & $\begin{array}{l}-.10^{\circ .} \\
(0.033)\end{array}$ & $\begin{array}{l}-.1^{.0} \\
(0.033)\end{array}$ & ${ }^{-.1^{* *}}$ & $\begin{array}{c}-.11^{\cdots} \\
(0.03)\end{array}$ & $\begin{array}{c}-.09^{2 .} \\
(0.04)\end{array}$ \\
\hline Legitimacy of field & & & $\begin{array}{l}48^{* * *} \\
(0.14)\end{array}$ & $\begin{array}{c}1.33^{\circ \cdots} \\
(0.03)\end{array}$ & $\begin{array}{c}2.17^{* *} \\
(0.36)\end{array}$ & $\begin{array}{l}2.15^{\cdots \cdot .} \\
(0.003)\end{array}$ \\
\hline Population & & & & $\begin{array}{l}.03^{* \ldots} \\
(0.00)\end{array}$ & $\begin{array}{l}.03^{\cdots} \\
(0.00)\end{array}$ & $\begin{array}{c}.03^{\cdots \cdot} \\
(0.009)\end{array}$ \\
\hline Population $2 / 1000$ & & & & $\begin{array}{c}-.09^{\cdots *} \\
(0.01)\end{array}$ & $\begin{array}{c}-.07^{\cdots} \\
(0.01)\end{array}$ & $\begin{array}{l}-.08^{\circ .} \\
(0.004)\end{array}$ \\
\hline Dispersion of researchers & & & & $\begin{array}{c}.001 \\
(0.002)\end{array}$ & $\begin{array}{c}-.01^{*} \\
(0.002)\end{array}$ & $\begin{array}{l}-.009^{*} \\
(0.001)\end{array}$ \\
\hline Cumulative knowledge & & & & & $\begin{array}{c}-.0024^{\ldots *} \\
(0.000)\end{array}$ & $\begin{array}{c}-.003^{\cdots} \\
(0.003)\end{array}$ \\
\hline Group size & & & & & & $\begin{array}{c}-.01 \\
(0.012)\end{array}$ \\
\hline Cumularive group producrivity & & & & & & $\begin{array}{c}-.0007 \\
(0.04)\end{array}$ \\
\hline Cumularive co-authors & & & & & & $\begin{array}{r}-.017 \\
(0.02)\end{array}$ \\
\hline P-level & .000 & .000 & .000 & .000 & .000 & .000 \\
\hline $\mathrm{df}$ & 4 & 6 & 7 & 10 & 11 & 14 \\
\hline Chi square & 18.0 & 263.7 & 273.8 & 540.7 & 610.0 & 614.1 \\
\hline
\end{tabular}

NOTE: 1.) Overall number of spells $=2976$; number of exirs $=604$.

2.) Figures in parentheses are sandard errors of estimates

3.) Significance level: ${ }^{*}<.05 ;{ }^{*}<.01 ; \cdots<.001$. 


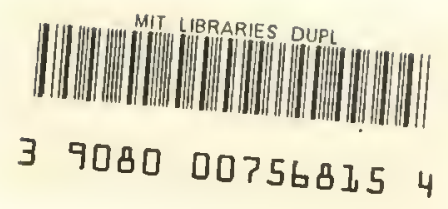






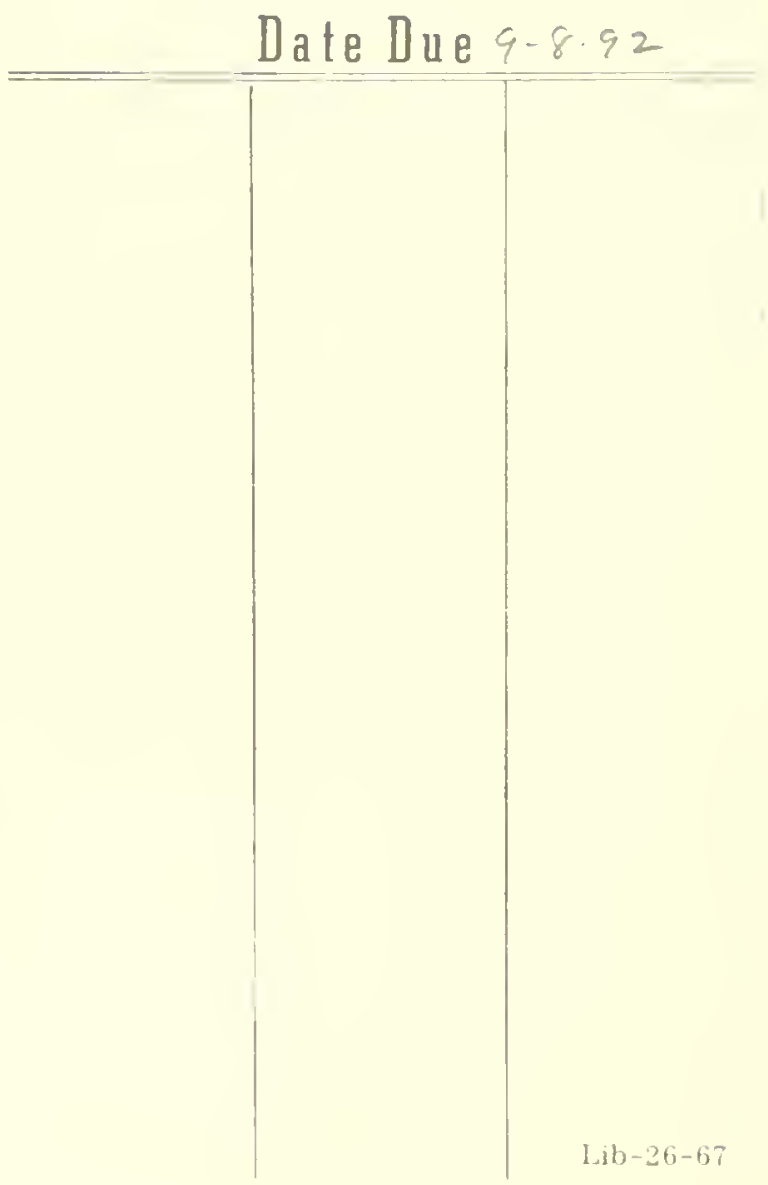




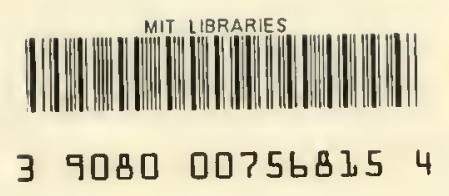


